\section{ALSO AVAILABLE FROM BLOOMSBURY}

Bloomsbury Companion to Analytic Philosophy, edited by Barry Dainton and Howard Robinson

Bloomsbury Companion to Metaphysics, edited by Neil A. Manson and Robert W. Barnard

ie Bloomsbury Companion to Philosophy of Science, edited by Steven French and Juha Saatsi

Critical Introduction to the Epistemology of Memory, Thomas D. Senor A Critical introduction to the Metaphysics of Time. Ben Curtis taphysics A Critical Translation with Kant's Elucidations, Selected Notes, id Related Materials, Alexander Baumgarten, translated and edited by Courtney D. Fugate and John Hymers

Time: A Philosophical Introduction, James Harrington

\section{Debates in the Metaphysics of Time}

\author{
EDITED BY
}

L. NATHAN OAKLANDER 


\section{Bloomsbury Academic \\ An imprint of Bloomsbury Publishing PIc \\ 50 Bedford Square 1385 Broadway

London New York \\ WC1B 3DP NY 10018 \\ UK USA \\ www.bloomsbury.com}

Bloomsbury is a registered trade mark of Bloomsbury Publishing Plc

First published 2014

(C) L. Nathan Oaklander and Contributors 2014

than Oaklander has asserted his right under the Copyright, Designs and Patents Act, 1988 , to be identified as the Editor of this work.

ights reserved. No part of this publication may be reproduced or transmitted in any $n$ or by any means, electronic or mechanical, including photocopying, recording, or nformation storage or retrieval system, without prior permission in writing from the publishers.

esponsibility for loss caused to any individual or organization acting on or refraining iction as a result of the material in this publication can be accepted by Bloomsbury or

$$
\text { the editor. }
$$

British Library Cataloguing-in-Publication Data

A catalogue record for this book is available from the British Library.

ISBN: HB: 978-1-7809-3741-0

PB: 978-1-7809-3490-7

ePDF: 978-1-7809-3748-9

ePub: 978-1-7809-3677-2

\section{Library of Congress Cataloging-in-Publication Data}

A catalog record for this book is available from the Library of Congress.

Typeset by Fakenham Prepress Solutions, Fakenham. Norfolk NR21 8NN Printed and bound in India 


\title{
5 \\ Becoming: Temporal, Absolute, and Atemporal
}

\author{
M. Oreste Fiocco
}

\section{Introduction}

here are two conspicuous and inescapable features of this world in which time is real. One experiences a world in flux, a transient world in which things constantly come into existence, change and cease to be. One also experiences a stable world, one in which how things are at any given moment is permanent, unchangeable. Thus, one can contemplate in silence-then be startled by a flash and accompanying boom-then return to silence, and although the flash and boom are gone, it seems indubitable that something remains unchanged, at least in so far as it must be true that a flash and boom precede this silent moment.

There is transience and permanence. Yet these two features of the world seem incompatible. However, focusing on one can yield only an objectionable metaphysics of time to the extent that the other, itself a compelling feature of the world, is neglected. The primary purpose of this chapter is to sketch a metaphysics of time that embraces both features. Given a certain view of the nature of reality and of the structure it contains, from a basis of uncontroversial claims about time and change, I show that utter stasis and continuous dynamism can both be genuine and objective features of reality.

Crucial to this undertaking is the notion of becoming, that is, coming into existence. I distinguish three distinct phenomena of becoming: temporal, absolute, and atemporal. The last is the least familiar of these; it is the phenomenon of coming into existence outside of time. Although the idea that there are things that do not exist in time is not unfamiliar, it is largely taken for 
granted that if anything comes into existence, it must do so in time. Indeed, I suspect many think that the idea of a thing coming to be outside of time is simply incoherent. It would be if becoming were a process-but it is not. In this chapter, I articulate and defend the notion of atemporal becoming. It is by means of this notion that one can develop a fully satisfactory metaphysics of time, one that honors both transience and permanence and finds for each its proper domain within the world.

A discussion of the fundamentals of the metaphysics of time requires an explicit account of what time itself is. So I begin with such. Making clear the nature of time per se enables me to distinguish time from temporal reality and to present the two generic positions regarding temporal reality. I then propound an account of atemporal reality, the world outside of time. Having laid this foundation, I consider the undeniable phenomenon of temporal becoming, which underlies the flux in the world, and discuss attempts to situate this phenomenon in different accounts of temporal reality. I maintain that the only feasible way of doing so is by recognizing absolute becoming. Absolute becoming, however, seems to compromise the patent stability of the world. This leads to the key notion of atemporal becoming. After illuminating this phenomenon, I defend its place in a fully satisfactory metaphysics of time.

\section{Time and temporal reality}

As a prologue, I make a brief statement of the view of the world in itselfreality as it is prior to any conceptualization by thinking beings or their linguistic or social interactions-that underlies the present discussion. Although I believe there are strong reasons for accepting this view, I leave its defense to another occasion; it is feasible enough for present purposes. I believe that the world in itself contains a great variety of individual substances, instances of genuine kinds of thing, and ways (both universal and particular) that these things are. Each entity has a nature determined by what it is and stands in relations to entities of the same and other categories. These relations and the constraints thereby placed on their relata is the structure in reality. All features of the world have an ontological basis in this structure and, in so far as they admit of explanation, are ultimately explicable in terms of it. This picture is robustly realist, then, about distinct categories (including substances, kinds, properties, and modes), the structure in the world and explanation.

A metaphysics of time is a theory of the peculiarly temporal features of the world, those that arise given that time is real. I maintain that a distinction between the world in time and the world outside it is crucial to a fully satisfactory metaphysics of time. In order to get purchase on this distinction, one needs an account of the nature of time itself. With such an account, one can articulate the relations between time and other entities-and see past the mere spatial connotations of "in" and "outside"-to acquire a better sense of the worldly structure associated with temporality.

\section{What time is}

Discussions of time are contentious. in so far as there is here a subject, though, there is some common ground from which discussion arises, certain phenomena that motivate inquiry and are thought to go together. The most conspicuous phenomenon associated with time is change. Change is an incontestable feature of the world. Moreover, what change is is uncontroversial: an entity changes if and only if it in itself is one way at one moment and an incompatible way at a distinct moment. Everyone who recognizes change can accept this account; it is neutral on any substantive issue.

Change is thought to require time. Although there has been debate regarding whether there could be time without change-and some accept there could' - no one maintains that there could be change without time. Thus, that change requires time seems a truism. I suspect some accept it because, in light of the foregoing account of change, they accept that there could be no moments without time; or perhaps they just conflate time, itself, with times, that is, moments. The former is more insightful. Regardless, however, of why the truism is accepted, it leaves open what time itself is.

Despite interest in time throughout the history of Western philosophy, there is very little discussion of time per se. This claim is perhaps surprising, but when one recognizes that investigations pertaining to time tend to focus on issues attendant on time-like change, becoming, tense, persistence, temporal experience-rather than time itself, one can see its truth. Some ecumenical account of time is needed, then; some account that illuminates these issues and unites the different factions all of whom take themselves to be investigating the metaphysics of time. In light of these considerations, I provide an account of time per se: I submit that time is a thing, namely the thing in virtue of which any entity changes. ${ }^{2}$ An entity might have, by its very nature, the capacity to change-but without time itself it could not change. Time is, therefore, the thing that makes change possible. It does so by yielding the moments required for change. Time itself is distinct from any moment or collection of moments.

This brief account of time itself has at least two benefits. It makes explicit the connection whereby change requires time and it also provides the ontological basis of a phenomenon, to wit, change, the complexity of which 
seems to be ill-suited to be taken as primitive. There is, in the structure of the world, some explanation of how change occurs and this explanation is rooted in time. Time itself is simple and essentially existent; by its very nature it must exist. ${ }^{3}$ Some might object to this account of time itself because of the hypostasis it requires. One should recognize, however, that this sort of objection is based on ontological scruples, pertaining to parsimony or perhaps an aversion to abstracta, rather than on any consideration arising from the metaphysics of time itself. Indeed, there is nothing objectionable about this account from the perspective of the metaphysics of time; it is wholly neutral in regards to any controversial issue. Therefore, in an attempt to propound a fully satisfactory metaphysics of time, I consider the proposed account of time per se to be not only acceptable but also illuminating.

\section{What temporal reality is: The world in time}

If time is the thing that makes change possible, there could be many entities that exist in virtue of time, for example, any moment that exists (or has any being whatsoever); any properties that are borne primarily by moments (e.g. being present, being past, being futurel and any relations that are borne primarily by moments (e.g. earlier than, later than, simultaneous with). Moreover, there are things that do not exist in virtue of time yet are intimately related to it in that they require a moment at which to exist, for example, any entity whose very nature includes the capacity to change. Such a thing is a temporal entity and exists at a moment if it exists at all. Temporal reality is all that exists in virtue of time and every temporal entity-it is the world in time. Note that despite being included in temporal reality, a moment itself is not a temporal entity, for no moment exists at a moment and so is not a thing that could change. Time itself is neither a temporal entity, for it exists at no moment, nor included in temporal reality, for nothing, including time, exists in virtue of itself.

I think the existence of time, as characterized above, is highly plausible (if not beyond dispute) and that it is this notion of time that those who accept that time is real accept. Similarly, I think the existence of temporal reality is highly plausible (if not beyond dispute). Anyone who bothers with a critical examination of time, then, recognizes both time and temporal reality. However, one needs to recognize the distinction between the two: time is a particular entity; temporal reality is a collection of entities (including concrete particulars, moments, temporal properties, temporal relations) essentially related to time. So with these ecumenical notions of time, temporal realityand change - there is a good deal of common ground in the metaphysics of time.
Yet, as noted above, discussions of time are contentious. One might accept the existence of both time and temporal reality as characterized and yet disagree about the extent or contents of temporal reality. For example, the metaphysics of time that I ultimately propose herein is one in which no more than a single moment of time ever exists (in any sense) and only the temporal property being present and the temporal relation simultaneous with are instantiated. Such a view is determined by a number of controversial considerations. I do not think it an exaggeration, however, to maintain that the source of all the contention in the metaphysics of time is a single ontological issue: whether things come into or go out of being simpliciter. Disagreement on this issue leads to two generic positions regarding the nature of temporal reality.

Those who deny that a thing comes into or goes out of being simpliciter believe that at no moment does anything that exists in time absolutely fail to be a constituent of reality. This is not to say that in this view each thing always exists, for there can indeed be moments at which a thing does not exist. However, even at these moments, that thing EXISTS (tenselessly) relative to some other moment. Each thing has a permanent, tenseless existence at any moment at which it ever exists. This leads to a position regarding temporal reality in which all the many moments of time-and everything that exists at them-are equally real; it is a view in which temporal reality is ontologically homogeneous. Proponents of this position are called B-theorists, eternalists, block theorists and, somewhat misleadingly, tenseless theorists. ${ }^{4}$

Those who believe that a thing comes into or goes out of being simpliciter accept that something, which in no way exists, can come into being at a moment or that a thing can cease to be in every way and, hence, bear no properties or stand in any relation to anything (including any moment). This leads to a view of temporal reality in which there are ontological differences in the world in time. Given that this position is based on difference, it admits of a variety of more specific views, the unifying feature of which is the supposition that temporal reality is ontologically heterogeneous. For example, the view that there is but one moment and nothing before or after it; the view that there are many moments of time with different ontological statuses; the view that this moment and what is prior to it have the same ontological status though what is subsequent to thismoment does not exist at all, all posit ontological heterogeneity in temporal reality. Presentists, A-theorists, growing block theorists and, perhaps, tensed theorists ${ }^{5}$ represent this generic position on temporal reality.

In both positions, a thing exists at the moments at which it exists. The key distinction between the two is the ontological status of a thing at some moment, $m$, at which it does not exist. In the former position, although it does not exist at $m$, it does EXIST (tenselessly) at some other moment: 
in the latter position, at $m$, it does not exist at all, in any way-it is not a constituent of reality. in light of this pivotal difference, it is perhaps clear what would motivate one to adopt the position that temporal reality is ontologically homogeneous: one's experience of a stable world, in which how things are at any given moment is permanent and unchangeable. Likewise, the motivation for the position that temporal reality is ontologically heterogeneous is one's experience of a world continuously in flux, in which how things are at any given moment is transient.

These two positions regarding the nature of temporal reality are incompatible. The position one adopts presumably turns on whether one regards permanence or transience as the dominant feature of a world in which time is real. But since both are irrefragable features of one's experience, to neglect either can lead only to an objectionable metaphysics of time. Fortunately, the appearance of a dilemma here is based on a false assumption. This is the assumption that how the world is, given that time is real, must be accounted for entirely by an account of temporal reality. This is false. There is more to the world than the world in time-what more there is provides the means of presenting a fully satisfactory account of a world in which time is real.

\section{Atemporality}

I have discussed the notions of time and of temporal reality in some detail in order to make clear the notion of atemporality, of existing outside of time, that is, without temporal reality. As mentioned above, this notion is, I believe, of the utmost importance to a satisfactory metaphysics of time.

\section{The world outside time}

A straightforward account of atemporality emerges from the foregoing. If a thing is in time, then it is related to time in a suitably intimate way. One such way is to be related as to partake of the very nature of time. Since time is just the thing that makes change possible, doing so by yielding moments, it is plausible that what it is to partake of the very nature of time is to exist at a moment. Hence, existence in time is existence at some moment. Every temporal entity, that is, every entity whose very nature includes the capacity to change, exists in time.

Since everything is related to everything else in some way (if in no other, at least in being similar with respect to being real), a thing outside of time does not fail to be related to time. Rather, such a thing is outside of time in that it fails to be related to time in a suitably intimate way; it fails to partake of the very nature of time. Since, again, time is just the thing that makes change possible - by yielding moments-a thing that fails to exist at a moment clearly fails to partake of time's nature. What it is, then, to not exist in time, to exist outside of time, is to exist but at no moment. As such, an entity that exists outside of time-an atemporal entity-fails to meet a necessary condition of change and so cannot change. An atemporal entity is just as real as a temporal one, but given their respective relations to time, the former is immutable whereas the latter is mutable.

\section{An attempt to reject atemporality altogether}

One might reject this notion of timelessness, or any other, because one might maintain that all entities are capable of changing in some way and, hence, exist at some moment. If this is correct, there simply are no atemporal entities and, a fortiori, no atemporality (and no atemporal becoming).

The claim that every entity is capable of changing is plausible only if one counts as change the gain (and corresponding loss) of any property contrary to one a thing has at some moment. If one were to do this, one would hold that when Xantippe goes from being wife to widow upon the death of Socrates that she has undergone a genuine change. This, however, does not accord with the uncontroversial account of change introduced above, for the properties being a wife and being a widow do not characterize Xantippe in herself. The putative change that Xantippe undergoes upon the death of Socrates needs to be distinguished from the sort of change Xantippe undergoes when, say, she stands up after sitting. In the latter case, the change arises from the gain of a property that is incompatible with one that Xantippe has in virtue of how she herself is. In the former case. the change does not arise in virtue of Xantippe herself; rather, in a clear sense, the "change" - so-called "Cambridge change" of a "Cambridge property" - - has crucially to do with something entirely distinct. In this context, one in which the bone of contention is the mutability of all things-whether it is compatible with the nature of each thing to change-the latter notion of change, the uncontroversial one presented above, is clearly the operative one. ${ }^{7}$

Bearing this notion in mind, there are some things-for example, numbers, properties, propositions, moments themselves-that, in so far as their natures are understood at all, seem to be incapable of change. It certainly seems that things of these kinds are not one way at one moment, then an incompatible way at another in virtue of how they themselves are. Indeed, I am aware of no consideration that even suggests that such things can undergo genuine change. ${ }^{8}$ in what follows, then, I take for granted that there are atemporal entities, things that exist without temporal reality, as real as anything else, but not at any moment. 


\section{Two views of timelessness (neither of which is adequate)}

So there is no good reason to think that everything must or can change. ${ }^{9}$ Nevertheless, one might still resist the proposed account of atemporality. There are traditionally two notions of timelessness. In one, an atemporal thing is eternal: it is supposed to exist outside of time, that is, at no moment. In the other, a timeless thing is sempiternal: it exists unchanging at each moment. Thus, one might acknowledge that there are immutable things, but maintain that such things still exist in time in the sense provided above: they exist unchanging at every moment.

The capacity to change, however, is such a basic feature of an entity that it is plausibly regarded as partially definitive of a thing's nature and so, in this way, essential to anything that has it. Thus, it is of the very nature of a mutable thing to be capable of changing, in that it is not possible for that very thing to exist as the very thing it is and yet lack the capacity to change. A mutable thing must be a temporal thing in that it must exist at a moment if it exists at all. Similarly, for those things that are incapable of changing, it is of their very nature to be incapable of changing. Nothing mutable is possibly immutable or vice versa; a fortiori, nothing mutable becomes immutable (or vice versa). Temporal and atemporal entities are necessarily mutually exclusive types of entity.

This is important for it provides grounds for rejecting the claim that atemporal entities are sempiternal, "timeless" yet existing at moments. If one assumes that an entity that exists at a moment is ipso facto susceptible to change, then it follows immediately that no atemporal entity can exist at a moment. If one forgoes this assumption, alternative considerations support the same conclusion. If an atemporal entity is essentially immutable, it is not immutable because it exists outside of time. Rather, it fails to exist at a moment because, by its very nature, it is not susceptible to change. If, however, one assumes that an atemporal entity exists unchanging at every moment, one is left to account for why it exists at a moment if it cannot change. The assumption that it exists in time is entirely gratuitous. The simpler view, in that it does not require one to account for what would be a perplexing feature of atemporal entities, is the one in which atemporal entities just do not, by their very nature, exist at moments. Perhaps those who accept sempiternal entities maintain that such things exist among the temporal entities-that is, at moments-because they see no other way to understand timeless structure in the world. But the preceding account of time itself provides the means to do so: timeless things exist, yet at no moment(s), for they are not related to time in a suitably intimate way.

There is, then, little motivation for maintaining that an immutable, atemporal entity exists at all moments. This does not mean, however, that I think the traditional notion of eternal existence provides an accurate account of atemporality. This notion brings with it the idea of essential existence, in that an eternal entity is supposed to be one that must exist by its very nature. It would be inappropriate to say that such a thing has always existed, for this is to characterize an atemporal entity with a temporal notion. But it is apt to say that such a thing has no origin; it simply has to be.

I want to clearly distinguish essential existence (and, thus, eternal existence) from timeless existence, for I believe there are things that are timeless that nevertheless have origins. Such things do not exist essentially, yet they exist, so they do, in a literal sense, become. However, they come into existence outside of time. Each is an example of atemporal becoming.

\section{Becoming: Temporal and absolute}

I fully admit that the notion of atemporal becoming likely sounds incoherent. The purpose of this chapter, though, is to show that not only is it coherent, but that atemporal becoming plays an important role in the metaphysics of time. Before expounding this phenomenon, it is helpful to discuss a vexed, but more familiar, one, namely temporal becoming. As observed at the outset, one of the conspicuous and inescapable features of a world in which time is real is a certain dynamism: one experiences a world in flux in which things constantly come into existence, change, and cease to be. Temporal becoming is standardly supposed to underlie this dynamism. An adequate account of this phenomenon makes clear the need for atemporal becoming.

\section{Dynamism: Change, temporal becoming, and novelty}

Change is indubitable. Since there can be no change without dynamism, both positions regarding the nature of temporal reality-that it is ontologically homogeneous and that it is ontologically heterogeneous-must provide some account of temporal becoming. In so far as temporal becoming is a real phenomenon, it has an ontological basis among the things that exist and the relations in which they stand. However, no thing is in itself dynamic, and no entity in isolation of every other thing changes. Certainly no property itself changes, nor any moment; even a paradigmatic mutable entity, a concrete individual substance, which obviously has the capacity to change, is not in itself dynamic. The dynamism in the world comes not from any thing, but arises from the relations in which entities stand. (Recall that in the operative account of change, change occurs when a substance bears incompatible 
properties at distinct moments.) Therefore, dynamism and the phenomenon of temporal becoming that underlies it are structural features of the world

This is apparent when one recognizes that temporal becoming is the coming into being of some entity at a moment. Since change requires a temporal entity, assuming (as seems plausible) that no mutable, that is, temporal, entity is essentially existent, it follows that change requires temporal becoming. If change is the mark of dynamism, this shows why temporal becoming is supposed to underlie the dynamism in the world.

As intimated by the discussion above, incompatible accounts of temporal becoming can be regarded as definitive of the two opposing positions regarding the nature of temporal reality. In one position, at any moment before a thing comes into existence at moment $m$, it EXISTS ${ }^{10}$ (tenselessly) at $m$; in the other, before a thing comes into existence at a moment, it is in no sense a constituent of reality. Both positions, then, provide some account of temporal becoming; moreover, partisans of both positions can accept the very same notion of change. However, in considering the dynamism in the world, one must consider more than merely temporal becoming and change. It is universally acknowledged-embraced by partisans of both positions on the nature of temporal reality-that there is an especial impression of novelty arising from being in a world in which time is real.

This impression of novelty has traditionally been characterized as a sense of flow or passage. Thus, D. C. Williams asserts that we are "immediately and poignantly involved in the jerk and whoosh of process, the felt flow of one moment into the next," 11 and J. J. C. Smart maintains that "certainly we feel that time flows." ${ }^{12}$ Tim Maudlin states that there is a "manifest fact that the world is given to us as changing, and time as passing." ${ }^{13}$ Bradford Skow characterizes the impression by observing that "Of all the experiences I will ever have, some of them are special. Those are the ones that I am having NOW. All those others are ghostly and insubstantial," ${ }^{14}$ and Laurie Paul observes that "I ... feel the cool breeze on my face. I feel the freshness of the cool breeze now, and, as the breeze dies down, I notice that time is passing." 15

This impression of novelty is crucially associated with the dynamism in time. A full account of this dynamism and, hence, a fully satisfactory metaphysics of time, needs to include not only accounts of temporal becoming and change, but also some account of this special sort of novelty. Although partisans of both positions regarding the nature of temporal reality agree that there appears to be a further dynamic feature of reality, they disagree on what is needed to account adequately for it. It is one of the most disputatious points in the metaphysics of time whether the position that temporal reality is ontologically homogeneous has the means to do so. A pivotal question, then, is how one who thinks that the world in time is ontologically homogeneous accounts for the impression of novelty, the phenomenon that, combined with temporal becoming and change, yields the experience of a world in flux.

\section{Novelty and ontological homogeneity of temporal reality}

If there are many moments of time and everything in temporal reality-all the many moments and anything that exists at any one of them-has the same ontological status, nothing in time is genuinely novel. Every mutable thing EXISTS (tenselessly) and is a/ways a constituent of reality, in the sense that at every moment each temporal entity EXISTS at some moment. Since there is nothing novei in reality itself, one must account for the impression of novelty by citing some interaction between a thinking being and a permanent feature of the world. Any novelty must be projected onto the world by one's subjective experience of it, presumably as one encounters a permanent thing or moment for the first time. Therefore, one must account for novelty in terms of the changes in thinking beings who EXIST (tenselessiy) at moments.

As is clear from their proposais to account for the impression of novelty, this point is recognized by proponents of the ontological homogeneity of temporal reality. J. J. C. Smart suggests that it is one's confusion regarding how certain predicates in natural language (like "is past", "is present," and "is future") work that is the basis of this novelty. ${ }^{16} \mathrm{D}$. H. Melior suggests that it is one's different beliefs at different moments that is the subjective "truth in the metaphysical falsehood that time flows." "17 the same vein, Laurie Paul suggests that the impression of novelty arises from "the way brains of conscious beings experience and interpret cognitive inputs from series of static events." ${ }^{18}$

But this approach does not seem feasible. Grant that it is some mental (or neuro-physiological) state of a thinking being that is the basis of the impression of novelty. This impression is distinctive in that it marks a particular moment as special (as novel). It can only do this, though, if no other moment is marked in the same way. However, assuming tempora reality is ontologically homogeneous, nothing in time is any more or any less real than anything else. This includes not only every thinking being, but aiso every mental state of every thinking being. If this is so, and the impression of novelty is inexorable, then at every moment at which one exists, one has the impression that that moment is novel. In which case, for any thinking being there are many moments marked as novel; indeed every moment at which one exists presents itself as novel. Thus, the mental state underlying the impression of novelty cannot be the source of one's sense that there is something special about this moment, now; for one has the same state (or a relevantly similar onel at every moment at which one EXISTS, and one EXISTS 
at many moments. An explanation of one's sense of the novelty of a particular moment-this one, now-is still needed.

The problem here indicates a much deeper problem for the position that temporal reality is ontologically homogeneous. The position does not present an accurate account of how one experiences a world in which time is real. Consider again Paul's account of the sense that time passes. At moment $m 1$, one feels the freshness of a cool breeze; at $m 2$, the breeze has died down to the extent that one no longer feels it. If both moments of time are equally real, one both FEELS a cool breeze (at $m 1$ ) and FEELS no breeze (at $\mathrm{m} 2$ ). One does not feel the breeze and feel no breeze simultaneously; nevertheless, both experiences are as real and so should be equally arresting. But, of course, one HAS no such odd and conflicting experience of a breeze and no breeze.

Nota bene (and this point cannot be stressed enough); It makes no difference that one experiences the cool breeze at $m 1$ and feels no breeze at $m 2$, for both moments are equally real and one is just as much at one moment, experiencing the cool breeze, as one is at the other, experiencing no breeze. ${ }^{19}$ (Nor does it make any difference if it is merely a temporal part of one at each moment, if a temporal part of a thinking being is sufficient for that thinking being to be at and experiencing a moment.) Yet at most a single moment is ever salient to one (in the familiar way). Even if one posits some sort of mental (or neurophysiological) mechanism that at each moment dampens one's experience of every other moment, one must account for the fact that one experiences each equally real moment, in order, as if new. So the need for an account of the basis of the impression of novelty is urgent, but given that in this position, such an account can only be in terms of the states of thinking beings in time, one does not seem forthcoming.

Therefore, it seems that if one accepts that temporal reality is ontologically homogeneous, one must posit something extraneous to any thinking beingsome objective feature of temporal reality-as the basis of the undisputed impression of novelty and the means of a plausible account of the phenomenology of being in time.

\section{Novelty and passage}

What the preceding section reveals is that there can be temporal becoming and much change in the world-and even a sort of ceasing to be in time, viz., EXISTENCE at some moments, but not at others-and yet there fail to be any real dynamism. The temporal becoming and change accepted by those who think temporal reality is ontologically homogeneous is consistent with an utter lack of novelty, both in the world itself and in one's experience of it. Many have conceded this point and in light of it have proposed that temporal reality includes a phenomenon whereby the things in time, primarily moments, gain and lose intrinsic properties in an orderly way, independently of any thinking being. This sort of objective change, traditionally regarded as true passage in time, is supposed by some to be the basis of the impression of novelty.

The inclusion of objective intrinsic temporal properties among the things in temporal reality has long been thought to be the definitive feature of the position in opposition to the one in which the world in time is ontologically homogeneous. Although this is indeed the difference between some (problematic) versions of the so-called A-theory and the B-theory of time, it is a mistake to think that this difference is the basic one in the metaphysics of time. If one accepts that an entity must exist in order to be any way whatsoever-including past, present, and future-then a view in which every moment and anything that exists at that moment has some intrinsic temporal property bears a greater affinity to the position that temporal reality is ontologically homogeneous (it entails it) than the one that posits ontological differences in the world in time..$^{20}$ This point is noticed by some, ${ }^{2 i}$ but overlooked by many.22

In this view, the objective basis of novelty in temporal reality is the continuous gain and subsequent loss, by moments, of the intrinsic (temporal) properties, pastness, presentness, futurity. It is crucial to recognize that nothing bears any one of these properties permanently. Thus, a moment that is future momentarily takes on the property of being present and then bears the property of being past land subsequently, perhaps, the properties associated with being further and further past). This is the traditional notion of the passage of time; it is explicated in terms of literal change.

This account of the dynamism in temporal reality is illustrated by several familiar metaphors: the moving spotlight-just as a spotlight illumines a particular (unchanging) area as it courses over a building, presentness "illumines" a single moment; a projected film-just as one (unchanging) frame of a film is shown as it passes the projector bulb, one moment is "shown" as it momentarily bears the property of being present; a flip-bookjust as one views as animated a series of static drawings as they quickly pass by, one "views" a sequence of unchanging moments as each takes on the property of presentness before becoming past. The images are well worn, as is the underlying idea: there can be dynamism in a sequence of unchanging things, if each, in succession, temporarily bears some special feature.

But one need only state the well-worn idea to raise concerns about its coherence. In any coherent account, what it is for something to have a feature temporarily is for that one thing to have the feature at one moment, $\mathrm{ml}$, and for that very thing to fail to have it at a distinct moment, $\mathrm{m} 2$. But 
moments themselves cannot undergo this sort of change. Even granting that a moment exists at itself, no moment can exist at a distinct moment, a fortiori, no moment can have any property-temporal or otherwise-temporarily. The incoherence of this view can be drawn out even more starkly. If the objective basis of novelty in temporal reality were the continuous gain and subsequent loss, by moments, of intrinsic temporal properties, then, given that no moment can exist at a distinct moment, a moment would have to have a given feature (say, presentness) temporarily in the sense that it has that feature at $m$ and subsequently fails to have that feature at $m$. But this is contradictory in two ways: nothing can both have and fail to have a feature at $m$; moreover, something at $m$ cannot be subsequent to something at $m$.

Any view in which equally real moments are supposed to change leads to contradiction. This is the key insight of McTaggart's discussion of the metaphysics of time and the significance of the paradox named for him. ${ }^{23}$ McTaggart thought, incorrectly, that contradiction here shows that time is unreal. Rather, it shows that an account of the nature of temporal reality, to wit, one in which it is ontologically homogeneous, is incompatible with this account of the dynamism and the undisputed sense of novelty associated with being in the temporal world. ${ }^{24}$ One might try to introduce a higherorder temporal dimension to resolve the incoherence, but this leads to an infinite regress of temporal dimensions. Even if such a regress is in itself not problematic, it cannot solve the problem here, for such a structure could include no novelty. The present task is to provide a plausible account of the ontological basis of the novelty of being in time.

Hence, the too familiar images of the "passage" of time are entirely misleading. In each case-the spotlight, the film, the flip-book-there are things that persist at different moments with different properties-a particular portion of a building, a frame on film, a drawing. Each thing has temporarily, in the standard sense, some property, though perhaps merely a relational one. One cannot make literal sense of these metaphors in the case of a series of moments; moments do not persist and change requires persistence.

This important point can be made in another way. Each of the familiar metaphors employs some process. Any sequence of changes that is appropriately considered a process requires the persistence of some entity through some stages of the process. (There can be different persistent entities at different stages of the same process, but persistence is required nonetheless). Therefore, a process is something that occurs in time, over time, that is, at distinct moments. But the objective basis of novelty in temporal reality cannot be something that occurs at distinct moments. One has the full impression of novelty at each moment-rather than partial impressions at distinct moments-and so the ontological basis of the dynamism in the world cannot be any process. Nor can the objective basis of novelty be something that occurs at a single moment, for if temporal reality is ontologically homogeneous, everything that occurs at a single moment is static and permanent. Even if temporal reality is ontologically heterogeneous, what occurs at a single moment is static. But if the objective basis of the experience of novelty cannot occur at distinct moments, nor at a single moment, then it cannot occur in time at all. In so far as there is an objective basis of the experience of novelty, then, it must be something that is not temporal yet happens to moments.

\section{Absolute becoming}

If there is real dynamism-novelty-in temporal reality, it cannot come through process, the mere change of equally real things that exist at different moments, nor can it come through the moments themselves taking on and shedding intrinsic temporal properties (or properties of any sort). Change itself cannot provide the ontological basis for the sort of dynamism that partisans of both accounts of the world in time acknowledge. If one insists that novelty come through change, one demands more from change than can that novelty come through change, occount provided above-a sequence of changeless moments with the same persistent entity above-a sequence of change can be fully accommodated by both accounts of temporal reality. One who takes the novelty in temporal reality seriously need not think that there is anything more to change. ${ }^{25}$ However, one must accept that there is, in a sense, more to temporal reality than a sequence of moments all of which EXIST (tenselessly).

If there is an ontological basis to the certain appearance of novelty, it arises through moments in time coming into and going out of existence completely. A moment comes into being, lasts but an instant, and then ceases to be entirely. It does not cease to be relative to some other moment even as it REMAINS a constituent of reality. It ceases in every sense to be a part of reality. This phenomenon of coming to be is absolute becoming. The name and original articulation of the notion comes from C. D. Broad. ${ }^{26}$

As observed at the end of the preceding section, the objective basis of novelty needs to be something that is not temporal yet happens to moments, despite their incapacity to change. Absolute becoming provides the means of accounting for what happens to them: they come into being despite previously existing in no sense. Given this phenomenon, there is literal novelty in temporal reality and not merely new acquaintance with something that EXISTS (tenselessly) at many moments. Absolute becoming is not the coming to be at a moment, which is temporal becoming, but rather the coming to be of a moment. This is no process and yet the source of dynamism and novelty. 
Therefore, the dynamism in the world is a structural feature: it is not found in anything in itself, rather it is found among the things that exist, in the relations they stand to one another-including failing to relate in any sense whatsoever (which occurs when, for example, a moment ceases to be a constituent of reality). Given absolute becoming, a moment comes into being and ceases to be, immediately replaced by a wholly novel moment. In so far as one must recognize absolute becoming to account for the impression of novelty in the world-and its objective ontological basis-one must reject the position that temporal reality is ontologically homogeneous. Thus, the world in time is ontologically heterogeneous.

\section{Atemporal becoming}

Although each moment lasts but an instant, before ceasing to be a constituent of reality, it does not follow that what exists at each moment goes out of existence with each moment. Familiar concrete objects persist through time, so literally the same one can exist at different moments. What it is for a mutable entity to come into being is for it not to exist (or EXIST) at any moment, then to exist at one. Regardless of one's account of temporal becoming, what it is for something to come into existence in time is for it to come to be at a moment. Existence at a moment is the mark of a temporal entity.

Yet each temporal entity, which has the capacity to change, presumably can be destroyed and. hence, cease to be. Consequently, everything that exists in time eventually ceases to be. If this is so, there appears to be no lasting stability, no true permanence in the world. This, however, is problematic. After all, there are two conspicuous and inescapable features of this world in which time is real. Just as much as one experiences a world in flux, one experiences a stable world. The phenomenon of absolute becoming might be the ontological basis of genuine novelty in the world, but, if this is so, the indubitable permanence in the world seems to be lost. One who acknowledges absolute becoming must account for the stability of a world in which time is real. It remains to be seen, though, whether a view that accepts that temporal reality is ontologically heterogeneous has the means to do so.

I believe the phenomenon of atemporal becoming reconciles radical, continuous novelty in a world in which time is real with abiding permanence. If temporal becoming, coming into being in time, is to come to be at a moment, then atemporal becoming, coming into being outside of time, is to come into being, but not at a moment. A thing that comes into being outside of time is an atemporal entity. Above, it was noted that the mark of a temporal being is the capacity to change; the mark, then, of an atemporal entity is immutability. An atemporal being is one that does not and could not possibly change. It comes into being outside of time because, by its very nature, it is the sort of thing that cannot change.

What must be noted immediately is that coming into existence is not any sort of change. An entity that comes into being is not first one waynon-existent-and then a different way-existent-having persisted through some change. Becoming is no sort of process; a fortiori, atemporal becoming is not either. Of course, once an atemporal entity comes into existence it cannot change. But the crucial point to recognize is that there is no contradiction in saying that a thing that comes into existence does so outside of time, that it undergoes no change in coming to be and, therefore, is an atemporal entity.

Note that it is a mistake to try to time, as it were, the coming into existence of an atemporal entity. It might be tempting to say that the existence of some new kind of thing comes into being simultaneously with the coming to be of the first instance, some individual substance, of that kind. Temptation here should be resisted, for this way of regarding the situation is misleading and confusing. The coming to be of the two entities, the new kind and its first instance, is not simultaneous, because what it is to be simultaneous is to occur at the same moment. In this case, however, one entity-the individual substance - comes to be at a moment, the other-its kind —comes to be, but at no moment at all. It is literally false that the two origins are simultaneous.

I fear that some will suspect chicanery. One might insist that coming to be seems like a process-something must change when a novel entity exists though it did not before-so the notion of atemporal becoming is just double-talk. I maintain, however, that any suspicions here must be based on unexamined and too coarse notions of becoming and process (and perhaps non-existence). The phenomenon of atemporal becoming articulated above is based on explicit and plausible accounts of change, time, and temporal becoming. Therefore, it seems to be a genuine phenomenon.

\section{Atemporal entities}

An atemporal entity is one that exists immutably outside of time. Such an entity might lack an origin or, as argued above, an atemporal entity might have an origin: it might come into being outside of time and EXIST (tenselessly) immutably. Examples of the former might be the number 2, God and the property of being self-identical or being real. Examples of the latter might be things like the property of being good or being salty or the kind water or platypus or microwave-oven or fan of the New York Yankees. 
In the present context, a particularly relevant kind of atemporal entity that has an origin is a simple fact. I have discussed simple facts in detail elsewhere, so I provide here only a very brief account of them. ${ }^{27}$ Simple facts are mereologically simple and ontologically independent entities that are both the truthmakers for every true representation and also provide, in many cases, the ontological basis of the structure in the world. Examples of simple facts are the simple fact that there is no tiger in my office (at $\mathrm{m})$, the simple fact that I am not eight feet tall (at $\mathrm{m}$ ), the simple fact that the branches on the tree outside my window are moving in the breeze (at $m$ ) and, importantly, the simple fact that Aristotle is a philosopher (at $m$ ). where $m$ is a moment that no longer exists. Such entities are of crucial importance because they are the ontological basis of the permanence in a world that also includes absolute becoming and radical novelty.

In such a world, every moment and every mutabie entity at some point ceases to be. However, there are simple facts that come into existence to ground every true account of every moment and everything in time. Given atemporal becoming - and the existence of simple facts—one who accepts that temporal reality is ontologically heterogeneous, and so can adequately account for the experience of novelty, can also account for the indubitable permanence in the world. Things, the temporal ones, come and go, but some things, the atemporal ones, abide.

\section{Conclusion}

Reality is structured: it is, in itself, a world of natured entities standing in relations. The proper understanding of these entities and their natures and relations enables one to see that there is time and change and mutable things; there are also immutable things, entities not intimately related to time. The proper understanding of process and its ontological basis, absolute becoming, enables one to distinguish temporal becoming from atemporal becoming.

Atemporal becoming is the phenomenon that reconciles the two seemingly irreconcilable features of being in a world in which time is real: there is flux and transience and there is stability and permanence. Every truth about some changing feature of the world is grounded by an unchanging and immutable entity in the atemporal world (viz., some simple fact). So transience is in the temporal world, permanence in the atemporal world. Reality includes both the temporal and atemporal.

I believe the pressing sense that reality is both transient and permanent, and the inability of the two general positions regarding the nature of temporal reality to account for this sense in themselves has been the source of much, if not all, of the contention in contemporary discussions about the metaphysics of time. If one takes the beginning of the modern development of the metaphysics of time to be McTaggart's seminal argument for the unreality of time, one sees from the outset the struggle to provide a satisfactory account of the dynamism in a world of static moments.

What has been neglected in the metaphysics of time is the notion that there is more to the world than the world in time, and the initially perplexing phenomenon of atemporal becoming. The preceding discussion is my attempt to redress this neglect and thereby sketch a fully satisfactory metaphysics of time, one that embraces both of the conspicuous and inescapable features of this world in which time is real. Thus, one can contemplate in silence-then be startled by a flash and accompanying boom-then return to silence, and although the flash and boom are gone in every sense, there is something that remains unchanged, a simple fact regarding the flash and boom that no longer exist. This fact, having come into existence outside of time, is as permanent and stable as a thing could be ${ }^{28}$

\section{Notes}

1 See, for example, Shoemaker (1969); for an opposing view, see Lowe $(2002$ 247-9). Time without change is consistent with the account of time per se I am about to present.

2 A thing is certain ways because of what it is and via this nature contributes to the structure in reality. I make no distinction between thing. entity. existent, or being; any difference in usage is merely stylistic.

3 In brief, the argument for this claim is that since change is actual, it must be possible; the thing that makes it possibie therefore must exist.

4 The tenseless theory is a misieading name for this position because it is based on a semantic thesis that is actually compatible with the other position on temporal reality about to be presented in the text. For a discussion of the tenseless theory, see Mellor (1981, 1998).

5 The tensed theory is a misleading representative of this class of views because it is based on a semantic thesis that is actually orthogonal to the key ontological issues. See the previous note.

6 These terms come from Peter Geach (see Geach 1969: 71-2) in (perhaps backhanded) acknowledgment of the Cambridge philosophers, like McTaggart and Russell, who employed the notions.

7 Note that there can be real changes that are relational. Changes incurred when a thing takes on a part that it did not have or when it simply moves when a thing takes on a part that it did cases, in virtue of how that thing itself is (how it is composed or where it is located). 
8 Quentin Smith argues that all entities, including abstract ones such as propositions, exist in time (see Smith 1998: 157-61). However, his argument for this is based on the claim that an object undergoes genuine change when it changes with respect to its "Cambridge properties." He is explicit about this (Smith 1998: 148). So he maintains that when / cease to believe a certain proposition, $p$, this is a change in $p$. But clearly what grounds this change is some difference in my mental states, not in how $p$ is in itself.

9 Given this real distinction between the world within time and the world without, I must disagree with Chisholm and Zimmerman, who maintain that there is no reason to take "tenselessness" seriously (Chisholm and Zimmerman 1997).

10 In the context of any discussion of the homogeneity of temporal reality, all verbs must be read as tenseless. I only put select verbs in ALL CAPS in order to emphasize their tenseless reading, but this does not mean the other verbs in that context are not tenseless. This point should be borne in mind throughout this chapter.

11 Williams (1951: 465-6)

12 Smart (1980: 3).

13 Maudlin (2007: 135).

14 Skow (2009: Section IV).

15 Paul (2010: 333). For further recognition of this impression of novelty, see, for example, Schlesinger (1982: 501, 515) and Mellor (1998: 66-7).

16 Smart (1967).

17 Mellor (1998: 66). Mellor (1981: 116) characterizes change in one's beliefs as the "psychological reality behind the myth of passage."

18 Paul (2010: 339).

19 For related discussion of this point, see Fiocco (2010).

20 Hence, I disagree with Laurie Paul when she maintains that "the nexus of a philosophical debate over the ontology of time" is whether the "temporal properties of now and passage exist" (Paul 2010: 338).

21 See, for instance, Skow (2012: 223), where Skow asserts that his "A-theory" of time is a "version of eternalism."

22 For a prominent example, see the work of D. H. Mellor $(1981,1998)$.

23 See McTaggart (1908).

24 Thus, Skow's view, which explicitly combines the ontological homogeneity of temporal reality with changing moments, seems problematic. See Note 21.

25 Pace Laurie Paul's claim at Paul (2010: 334).

26 See Broad (1938: ch. 35, vol. II). For discussion of the notion, see Savitt (2002: 159ff.) and Fiocco (2007). Savitt interprets Broad's account of absolute becoming very differently than I do.

27 See Fiocco (2014).

28 I would like to thank Michael Brent and Nathan Oaklander for their interesting and insightful comments on a draft of this chapter.

\section{References}

Broad, C. D. (1938), An Examination of McTaggart's Philosophy. Cambridge: Cambridge University Press.

Chisholm, R. and Zimmerman, D. (1997), "Theology and tense," Noûs, 31, 262-5.

Edward, P. (ed.) (1967). The Encyclopedia of Philosophy. New York: Macmilian.

Fiocco, M. O. (2007). "Passage, becoming and the nature of temporal reality," Philosophia, 35, 1-21.

-(2010). "Temporary intrinsics and relativization," Pacific Philosophical Quarterly. 91, 64-77.

-(2014). "On Simple Facts," Res Philosophica, 91(3).

Geach, P. (1969), God and the Soul. London: Routledge.

van Inwagen. P. (ed.) (1980), Time and Cause: Essays Presented to Richard Taylor. Dordrecht: Reidel.

Le Poidevin, R. (ed.) (1998), Questions of Time and Tense. Oxford: Oxford University Press.

Lowe, E. J. (2002), A Survey of Metaphysics. Oxford: Oxford University Press.

Maudlin, T. (2007). The Metaphysics within Physics. New York: Oxford University Press.

McTaggart, J. M. E. (1908), "The unreality of time," Mind, 18, 457-84.

Mellor, D. H. (1981), Real Time. Cambridge: Cambridge University Press.

-11998), Real Time II. London and New York: Routledge.

Paul, L. (2010), "Temporal experience," Journal of Philosophy, 107, 333-59.

Savitt, S. (2002), "On Absolute Becoming and the Myth of Passage," in Craig Callender (ed.), Time, Reality and Experience. Cambridge: Cambridge University Press, pp. 153-67.

Schlesinger, G. (1982), "How time flies," Mind, 91, 501-23.

Shoemaker, S. (1969), "Time without change," Journal of Philosophy, 66, 363-81.

Skow, B. (2009). "Relativity and the moving spotlight," Journal of Philosophy, $106,666-78$.

-(2012). "Why does time pass?". Noûs, 46, 223-42.

Smart, J. J. C. (1967). "Time," in P. Edward (ed.). The Encyclopedia of Philosophy. New York: Macmillan.

-(1980), "Time and Becoming," in P. van Inwagen, Time and Cause: Essays Presented to Richard Taylor. Dordrecht: Reidel, p. 3-15

Smith, O. (1998), "Absolute Simultaneity and the Infinity of Time," in R. Le Poidevin (ed.), Questions of Time and Tense. Oxford: Oxford University Press, pp. $135-83$.

Williams. D. C. (1951), "The myth of passage," Journal of Philosophy, 48, 457-72. 